Article

\title{
Biological and Pathological Studies of Rosmarinic Acid as an Inhibitor of Hemorrhagic Trimeresurus flavoviridis (habu) Venom
}

\author{
Hnin Thanda Aung ${ }^{1}$, Toshiaki Nikai $^{1}$, Yumiko Komori ${ }^{1}$, Tsunemasa Nonogaki $^{2}$, \\ Masatake Niwa ${ }^{1}$ and Yoshiaki Takaya ${ }^{1, *}$
}

1 Faculty of Pharmacy, Meijo University, 150 Yagotoyama, Tempaku, Nagoya, 468-8503, Japan; E-Mails: hninthandaaung07@gmail.com (H.T.A.); nikai@meijo-u.ac.jp (T.N.); ykomori@meijo-u.ac.jp (Y.K.); masa@meijo-u.ac.jp (M.N.)

2 College of Pharmacy, Kinjo Gakuin University, 2-1723 Omori, Moriyama, Nagoya, 463-8521, Japan; E-Mail: tunenono@kinjo-u.ac.jp

* Author to whom correspondence should be addressed; E-Mail: ytakaya@meijo-u.ac.jp; Tel.: +81-52-839-2740; Fax: +81-52-839-2740.

Received: 2 September 2010; in revised form: 5 October 2010 / Accepted: 22 October 2010 / Published: 25 October 2010

\begin{abstract}
In our previous report, rosmarinic acid (RA) was revealed to be an antidote active compound in Argusia argentea (family: Boraginaceae). The plant is locally used in Okinawa in Japan as an antidote for poisoning from snake venom, Trimeresurus flavoviridis (habu). This article presents mechanistic evidence of RA's neutralization of the hemorrhagic effects of snake venom. Anti-hemorrhagic activity was assayed by using several kinds of snake venom. Inhibition against fibrinogen hydrolytic and collagen hydrolytic activities of $T$. flavoviridis venom were examined by SDS-PAGE. A histopathological study was done by microscopy after administration of venom in the presence or absence of RA. RA was found to markedly neutralize venom-induced hemorrhage, fibrinogenolysis, cytotoxicity and digestion of type IV collagen activity. Moreover, RA inhibited both hemorrhage and neutrophil infiltrations caused by T. flavoviridis venom in pathology sections. These results demonstrate that RA inhibited most of the hemorrhage effects of venom. These findings indicate that rosmarinic acid can
\end{abstract}


be expected to provide therapeutic benefits in neutralization of snake venom accompanied by heat stability.

Keywords: rosmarinic acid; snake venom; hemorrhage; metalloproteinase; Argusia argentea

\section{Introduction}

Envenomation resulting from snakebites is an important public health hazard in many regions, particularly in tropical and subtropical regions [1-3]. Snake envenomation causes various pathophysiological changes such as inflammation, increased body temperature, hemorrhage, necrosis, nephrotoxicity, cardiotoxicity, haemostatic changes and ultimately death [4]. Hemorrhage is a common symptom associated with local tissue damage in snake poisoning by Viperidae. In severe poisoning, hemorrhage can be observed in many internal organs [5,6]. Hemorrhage can occur as a result of cytotoxicity of the venom on endothelial cells, and a degradation of the basement membrane of the vein due to the venom acting as a metalloproteinase. In many countries, plant extracts have been traditionally used in the treatment of snakebite envenomations [7-9], although only a few cases have been scientifically validated. The present study aims to examine the venom neutralization potential of rosmarinic acid (RA) isolated from a methanolic extract of Argusia argentea [10] and its mode of action.

\section{Materials and Methods}

\subsection{Materials}

Trimeresurus flavoviridis (habu) venom (Okinawa), Gloydius blomhoffii venom and Bitis arietans venom were purchased from Japan Snake Institute, Gunma. Crotalus atrox venom was purchased from Sigma-Aldrich. Hemorrhagic toxin b $(\mathrm{HT} b)$ from C. atrox venom was prepared by the method reported previously [11]. Bilitoxin-2 and $\mathrm{Ac}_{1}$-proteinase were isolated using our methods reported previously [12,13] for Agkistrodon bilineatus venom and Deinagkistrodon acutus venom, respectively. Hemorrhagic toxin-1 (HT-1) was obtained from B. arietans venom [14]. Human and bovine fibrinogens were supplied by Sigma-Aldrich, Tokyo, Japan. Type IV collagen was purchased from Nitta Gelatin Inc. Cryo-preserved human umbilical vein endothelial cells (HUVEC), its respective cell culture media (HuMedia EB-2), other cell culture supplements, and reagents were obtained from Kurabo (Osaka, Japan). The cell counting kit was purchased from Dojindo (Kumamoto, Japan). Other chemicals were of analytical grade from commercial sources. All experiments involving the use of animals were carried out in compliance with the guidelines for animal experiments of Faculty of Pharmacy, Meijo University. 


\subsection{Rosmarinic Acid}

Rosmarinic acid (RA) was isolated and purified from methanolic extract of Argusia argentea as reported previously [10]. A voucher sample has been deposited in the Herbarium of the Faculty of Pharmacy, Meijo University, Japan.

\subsection{Anti-hemorrhagic Activity Assay}

Anti-hemorrhagic activity was assayed by the method of Bjarnason and $\mathrm{Tu}$ [15] using ddY mice of $20 \mathrm{~g}$ average weight. Two groups of four mice were used for the experiment. All crude venom solutions of T. flavoviridis venom, C. atrox venom, G. blomhoffii venom and B. arietans venom, were prepared at a concentration of $0.14 \mathrm{mg} / \mathrm{mL}$ in saline. Concentrations of purified hemorrhagic toxin solutions were as follows: HTb $(0.41 \mathrm{mg} / \mathrm{mL})$, bilitoxin-2 $(2.75 \mu \mathrm{g} / \mathrm{mL})$, HT-1 $(0.29 \mathrm{mg} / \mathrm{mL})$, and $\mathrm{Ac}_{1}$-proteinase $(1.04 \mathrm{mg} / \mathrm{mL})$. A test solution was prepared by mixing the venom solution or the toxin solution $(50 \mu \mathrm{L})$ and RA $(0.5 \mathrm{mg} / \mathrm{mL}$ in $10 \%$ DMSO-saline, $50 \mu \mathrm{L})$ followed by 10 min incubation at $37^{\circ} \mathrm{C}$. These test solutions $(100 \mu \mathrm{L})$ were injected subcutaneously (s.c.) in the abdomen of mice. Similarly, a group of mice which were injected with a venom solution without RA was used as a control group, and also a group which was only injected with $10 \%$ DMSO-saline $(50 \mu \mathrm{L})$ served as a blank group. Prior to this study, effects of DMSO at several concentrations were investigated, and DMSO at less than $10 \%$ was found to cause no significant inactivation of venom. After $24 \mathrm{~h}$, mice were euthanized by inhalation of chloroform, the skin covering the abdomen was removed and hemorrhagic lesions were analyzed as follows. The area of the lesion was estimated by major and minor axes measurements, since the shape of the lesions are always amorphous, like an ellipse.

\subsection{Fibrinogen Hydrolytic Activity Assay}

Fibrinogen hydrolytic activity was assayed by the method of Ouyang and Teng [16]. A solution of $0.1 \%$ human fibrinogen in $50 \mathrm{mM}$ Tris- $\mathrm{HCl}$ buffer $(\mathrm{pH} 7.5)(1 \mathrm{~mL})$ and a venom solution $(50 \mu \mathrm{L}$ of $0.21 \mathrm{mg} / \mathrm{mL}$ of $T$. flavoviridis venom or $5.5 \mu \mathrm{g} / \mathrm{mL}$ of bilitoxin-2) were incubated in the presence or absence of RA $(0.5 \mathrm{mg} / \mathrm{mL})$ at $37{ }^{\circ} \mathrm{C}$. At various time intervals, aliquots of $100 \mu \mathrm{L}$ of denaturing solution (10 mM phosphate buffer, $\mathrm{pH} 7.2$, containing $10 \mathrm{M}$ urea, 4\% sodium dodecyl sulfate (SDS), and $4 \% \beta$-mercaptoethanol) were added. This solution was incubated at $37{ }^{\circ} \mathrm{C}$ for $6 \mathrm{~h}$ and then run on $10 \%$ polyacrylamide slab gel electrophoresis. Electrophoresis was carried out for $2 \mathrm{~h}$ with a current of $25 \mathrm{~mA}$ per slab gel. Bromophenol blue (BPB) solution was used as an indicator.

\subsection{Collagen Hydrolytic Activity Assay}

Collagen hydrolytic activity was assayed as follows. Sodium hydrogen carbonate $(60 \mu \mathrm{L}, \mathrm{pH} 12)$ was added to $0.3 \%$ type IV collagen $(0.9 \mathrm{~mL})$ and adjusted to $\mathrm{pH} 8$. Aliquots of type IV collagen were incubated with $T$. flavoviridis venom $(0.21 \mu \mathrm{g} / \mathrm{mL})$ in the presence or absence of RA $(0.5 \mathrm{mg} / \mathrm{mL})$. At various time intervals, aliquots of $100 \mu \mathrm{L}$ of denaturing solution $(10 \mathrm{mM}$ phosphate buffer, $\mathrm{pH} 7.2$, 
containing $10 \mathrm{M}$ urea, 4\% SDS, and 4\% $\beta$-mercaptoethanol) were added. This solution was boiled for $3 \mathrm{~min}$ and run on SDS-PAGE using a 7.5\% polyacrylamide slab gel electrophoresis.

\subsection{Cytotoxic Action on HUVEC}

The effects of RA and T. flavoviridis venom on cultured human umbilical vein endothelial cells (HUVEC) were investigated [17-19]. Frozen HUVEC were cultured and maintained in commercially available media, HuMedia-EB2, supplemented with fetal calf serum ( $2 \% \mathrm{v} / \mathrm{v}), \mathrm{hEGF}(10 \mathrm{ng} / \mathrm{mL})$, hFGF-B $(5 \mathrm{ng} / \mathrm{mL})$, hydrocortisone $(1 \mu \mathrm{g} / \mathrm{mL})$, heparin $(10 \mu \mathrm{g} / \mathrm{mL})$, gentamicin $(50 \mu \mathrm{g} / \mathrm{mL})$, and amphotericin B $(50 \mathrm{ng} / \mathrm{mL})$. At confluency, cells were trypsinized, washed with the same medium and then resuspended in growth media. These cells were seeded in 96-multiwell plates $\left(5 \times 10^{3}\right.$ cells per well in $100 \mu \mathrm{L}$ medium) and were allowed to attach and reach log phase of growth. Aliquots of venom and RA to be assayed were diluted in saline and were sterilized by filtration with cellulose acetate $0.22 \mu \mathrm{m}$ membrane filters. Various concentrations of RA $(0.5,0.25,0.125,0.06,0.03 \mathrm{mg} / \mathrm{mL}$ in $10 \%$ DMSO-saline) in the presence or absence of $T$. flavoviridis venom $(0.14 \mathrm{mg} / \mathrm{mL})$ were added to each well in $100 \mu \mathrm{L}$ medium. The plate was incubated at $37{ }^{\circ} \mathrm{C}$ under $5 \% \mathrm{CO}_{2}$ atmosphere for $17 \mathrm{~h}$. Ten microliters of cell counting kit- 8 was added to each well, and the microplate was incubated for $1 \mathrm{~h}$, after which cell densities were measured at $450 \mathrm{~nm}$ using Bio-RAD Model 550 MicroplateR eader.

\subsection{Histopathological Study}

Histopathological study for RA was performed by intramuscular (i.m.) injection of T. flavoviridis venom solution into the medial aspect of the thigh muscle of ddY strain white mice. Histopathological study of muscle was conducted in three groups. Group A was injected with the venom $(0.21 \mathrm{mg} / \mathrm{mL}$, $100 \mu \mathrm{L})$, while group B was injected with RA $(0.5 \mathrm{mg} / \mathrm{mL}, 100 \mu \mathrm{L})$. Group C was injected with a mixture of the venom $(0.41 \mathrm{mg} / \mathrm{mL}, 50 \mu \mathrm{L})$ and $\mathrm{RA}(0.25 \mathrm{mg} / \mathrm{mL}, 50 \mu \mathrm{L})$. Test solutions were preincubated at $37^{\circ} \mathrm{C}$ for $10 \mathrm{~min}$ before injection. The mice were killed by chloroform inhalation $24 \mathrm{~h}$ after injection. Tissue samples were immediately fixed in buffered formate fixative for $24 \mathrm{~h}$ at room temperature. The tissue was then washed for $4 \mathrm{~h}$ in running water, dehydrated in an autotechnicon, and stained with hematoxylin and eosin for observation under light microscope.

\subsection{Heat Stability}

RA $(0.5 \mathrm{mg} / \mathrm{mL})$ in $10 \%$ DMSO-saline was heated at $37{ }^{\circ} \mathrm{C}, 50{ }^{\circ} \mathrm{C}$ and $100{ }^{\circ} \mathrm{C}$ for $10 \mathrm{~min}$, respectively. Fifty microliters of each heat-treated RA solution was mixed with $T$. flavoviridis venom $(0.21 \mathrm{mg} / \mathrm{mL}, 50 \mu \mathrm{L})$ and incubated at $37^{\circ} \mathrm{C}$ for $10 \mathrm{~min}$. An aliquot of $0.1 \%$ human fibrinogen in $50 \mathrm{mM}$ Tris-HCl buffer, $\mathrm{pH} 7.5$ was added to each test tube. The reactions were stopped by adding $100 \mu \mathrm{L}$ of denaturing solution (10 mM phosphate buffer, $\mathrm{pH} 7.2$, containing $10 \mathrm{M}$ urea, 4\% SDS, and 4\% $\beta$-mercaptoethanol). These solutions were incubated at $37{ }^{\circ} \mathrm{C}$ for $6 \mathrm{~h}$ and then run on $10 \%$ polyacrylamide slab gel electrophoresis. The venom solution without a sample was also subjected to 
SDS-PAGE for comparison. Moreover, by using RA $(0.5 \mathrm{mg} / \mathrm{mL})$, which was treated at $100{ }^{\circ} \mathrm{C}$, antihemorrhage activity was also examined as mentioned above.

\subsection{Assay for Edema Activity}

Hind-paw edema activity was assayed by the method of Ho et al. [20]. Four ddY strain white mice (20-23 g) were individually injected in the right foot pad with Trimeresurus elegans venom $(12.5 \mu \mathrm{g}$ in $50 \mu \mathrm{L}$ of $10 \%$ DMSO-saline). An equal volume of $10 \%$ DMSO saline was injected into the left paws as control. Inhibition assays were performed by preincubated rosmarinic acid $(0.5 \mathrm{mg} / \mathrm{mL}$ in $10 \%$ DMSO saline) with toxin for $10 \mathrm{~min}$ at $37^{\circ} \mathrm{C}$. The volume of each paw was measured with a slide caliper. The degree of paw swelling was expressed as \% increase of the initial paw volume.

\section{Results}

\subsection{Inhibitory Activity of RA on Crude Snake Venoms and Purified Hemorrhagic Toxins}

When crude venom (T. flavoviridis (habu) venom, C. atrox venom, G. blomhoffii venom, and B. arietans venom) or purified toxin, (HTb, bilitoxin-2, HT-1 and Ac $_{1}$-proteinase) was injected s.c. in the abdomen of mice, a distinct hemorrhagic lesion was observed (Figure 1c) [10]. No hemorrhagic spots were produced after s.c. injection of crude venom or purified toxin with RA (Figure 1b). RA effectively inhibited the hemorrhagic activities of crude venoms as well as purified hemorrhagic toxins.

Figure 1. Inhibitory activity of RA on T. flavoviridis venom (a) Structure of rosmarinic acid, (b) T. flavoviridis venom with RA, (c) T. flavoviridis venom without RA.

(a)<smiles>O=C(/C=C/c1ccc(O)c(O)c1)O[C@H](Cc1ccc(O)c(O)c1)C(=O)O</smiles>

Rosmarinic acid (RA) (b)

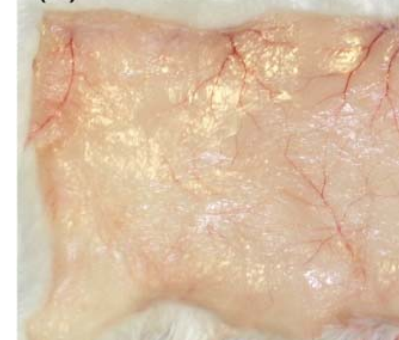

(c)

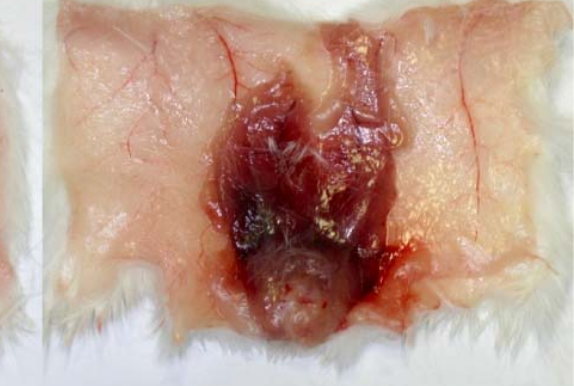

\subsection{Inhibition of Fibrinogen Hydrolytic Activity}

When human fibrinogen was incubated with $T$. flavoviridis venom, the A $\alpha$ band of the fibrinogen disappeared on SDS-PAGE, whereas the B $\beta$ chain and $\gamma$ chain were essentially unaffected (Figure 2a). The venom with RA did not reveal any apparent degradation of human fibrinogen (Figure 2b). RA also inhibited A $\alpha$ hydrolysis by bilitoxin-2 (Figure $2 \mathrm{c}$ and $2 \mathrm{~d}$ ). 
Figure 2. Effect of RA on human fibrinogen hydrolytic activities by $T$. flavoviridis venom and bilitoxin-2. 10\% SDS-PAGE of time-dependent digestion of human fibrinogen by T. flavoviridis venom and bilitoxin-2 in the presence or absence of RA. (a) T. flavoviridis venom without RA; (b) T. flavoviridis venom with RA; (c) bilitoxin-2 without RA; (d) bilitoxin-2 with RA. Molecular weight makers of 97, 66, 43, 30, 20.1, and $14.4 \mathrm{kDa}$ were used.
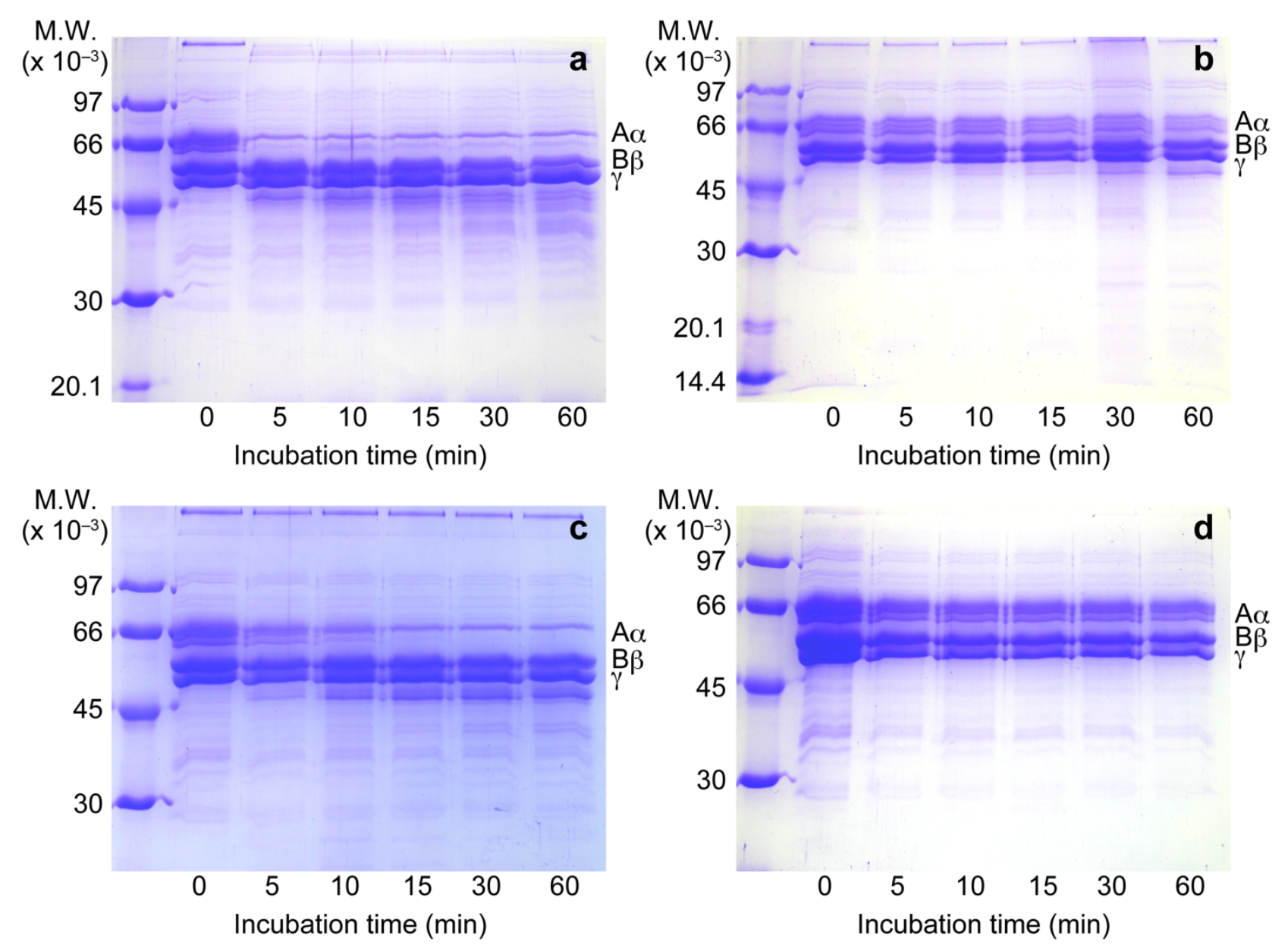

\subsection{Inhibition of Venom Cytotoxic Action on HUVEC}

RA alone had no effect on the viability of HUVEC, but it markedly protected HUVEC from the toxic effects of $T$. flavoviridis venom $(0.14 \mathrm{mg} / \mathrm{mL})$ at all concentrations of RA tested $(0.50,0.25$, $0.125,0.06$, and $0.03 \mathrm{mg} / \mathrm{mL}$ ) (Figure 3 ). The maximum $(84.2 \%$ ) protective effect of RA was exhibited with RA at $0.5 \mathrm{mg} / \mathrm{mL}$.

\subsection{Inhibition of Type IV Collagen Hydrolytic Activity}

Type IV collagen was incubated with $T$. flavoviridis venom for different periods of time. The venom completely degraded type IV collagen (104 kDa), especially over $1 \mathrm{~h}$, and degradates with smaller molecular weights (43 and $35 \mathrm{kDa}$ ) appeared, as shown in Figure 4a. In the presence of RA $(0.5 \mathrm{mg} / \mathrm{mL})$, type IV collagen was not digested by incubation with the venom (Figure $4 \mathrm{~b})$. 
Figure 3. Effects of RA against the cytotoxic actions of T. flavoviridis venom on HUVEC.

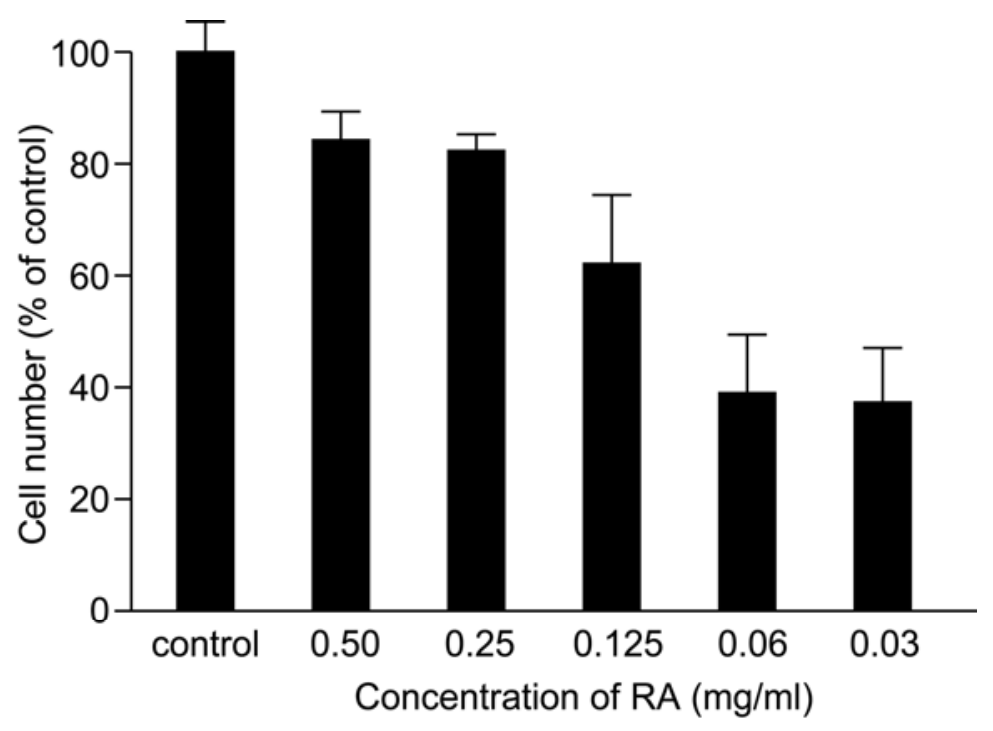

Figure 4. Effect of RA on type IV collagen hydrolytic activity by $T$. flavoviridis venom. $7.5 \%$ SDS-PAGE of time-dependent digestion of type IV collagen by $T$. flavoviridis venom in the presence or absence of RA. (a) venom without RA, (b) venom with RA. Molecular weight makers of $97,66,43$, and $30 \mathrm{kDa}$ were used.
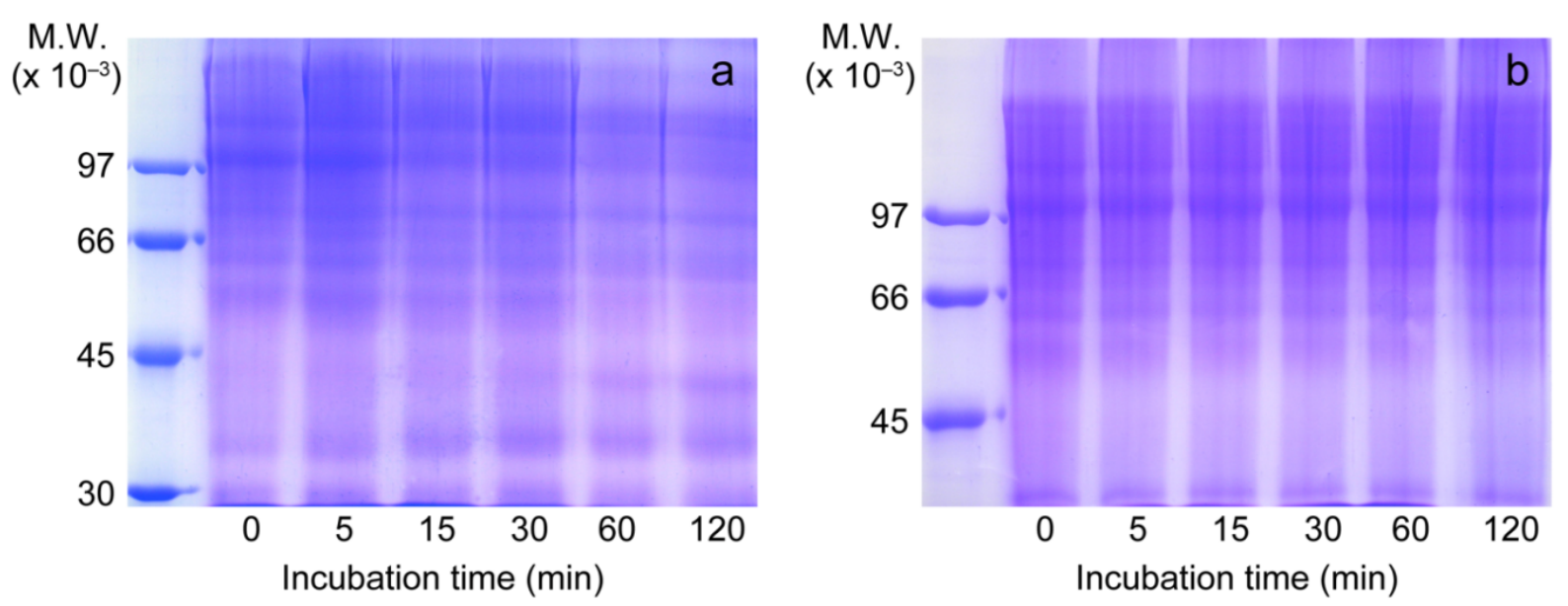

\subsection{Histological Study of $\mathrm{T}$. flavoviridis Venom and the Effect of RA}

Both hemorrhage and neutrophil infiltrations were observed in a wide area (of the circle) after injection of $T$. flavoviridis venom $(0.21 \mathrm{mg} / \mathrm{mL}$ ) (Figure $5 \mathrm{a}$ ). The result showed normal musculature devoid of hemorrhage and neutrophils in the muscle fibers after injection of RA $(0.5 \mathrm{mg} / \mathrm{mL})$ (Figure $5 \mathrm{~b}$ ). There was no hemorrhage or neutrolphil infiltration in the muscle fibers after injection of a mixture of the venom $(0.41 \mathrm{mg} / \mathrm{mL})$ and RA $(0.5 \mathrm{mg} / \mathrm{mL}$, or $0.25 \mathrm{mg} / \mathrm{mL}$; Figure $5 \mathrm{c})$. 
Figure 5. Histological results of thigh muscle after (a) injection of T. flavoviridis venom $(0.21 \mathrm{mg} / \mathrm{mL})$ alone $(\mathbf{b})$ injection of RA $(0.5 \mathrm{mg} / \mathrm{mL})$ alone (normal muscle), (c) injection of a mixture of RA $(0.25 \mathrm{mg} / \mathrm{mL})$ and the venom $(0.41 \mathrm{mg} / \mathrm{mL})$.

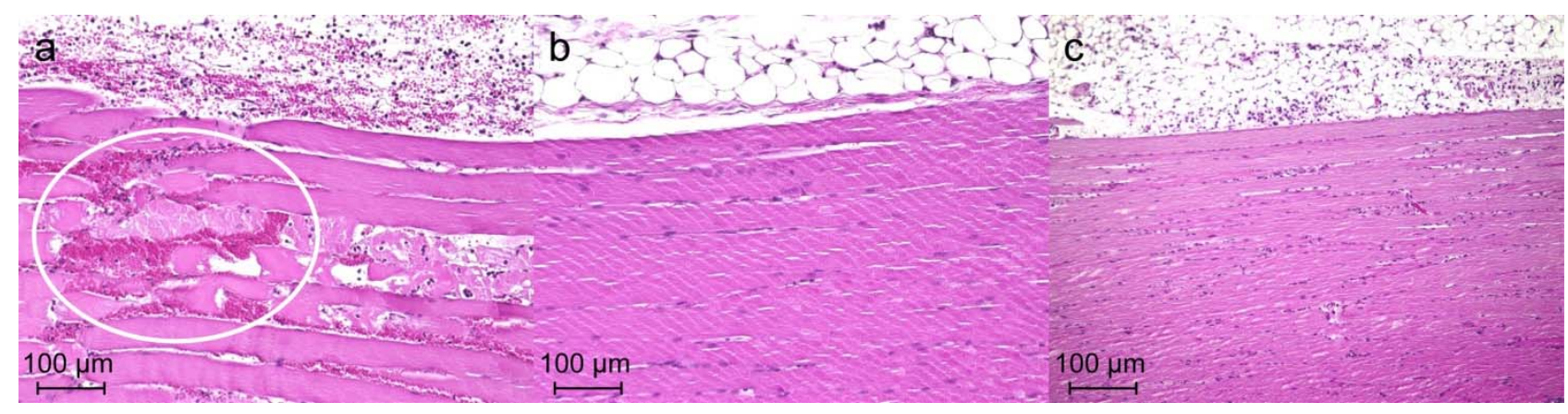

\subsection{Heat Stability of $R A$}

RA, which was heated at various temperatures, was incubated with human fibrinogen and T. flavoviridis venom. RA inhibited the digestion of $\mathrm{A} \alpha$ chain of human fibrinogen after treatment at each temperature (Figure 6). RA $\left(0.5 \mathrm{mg} / \mathrm{mL}\right.$ ), which was heated at $100^{\circ} \mathrm{C}$ for $10 \mathrm{~min}$, also showed complete inhibition against $T$. flavoviridis venom.

Figure 6. Heat stability study of RA by human fibrinogen digestion by $T$. flavoviridis venom. RA was heated at $37{ }^{\circ} \mathrm{C}, 50{ }^{\circ} \mathrm{C}$, or $100{ }^{\circ} \mathrm{C}$, then $\mathrm{RA}(0.5 \mathrm{mg} / \mathrm{mL})$ was mixed with human fibrinogen and venom $(0.21 \mathrm{mg} / \mathrm{mL})$, and the solution was incubated at $37{ }^{\circ} \mathrm{C}$ for $10 \mathrm{~min}$. Aliquots were subjected to SDS-PAGE (7.5\% gel).

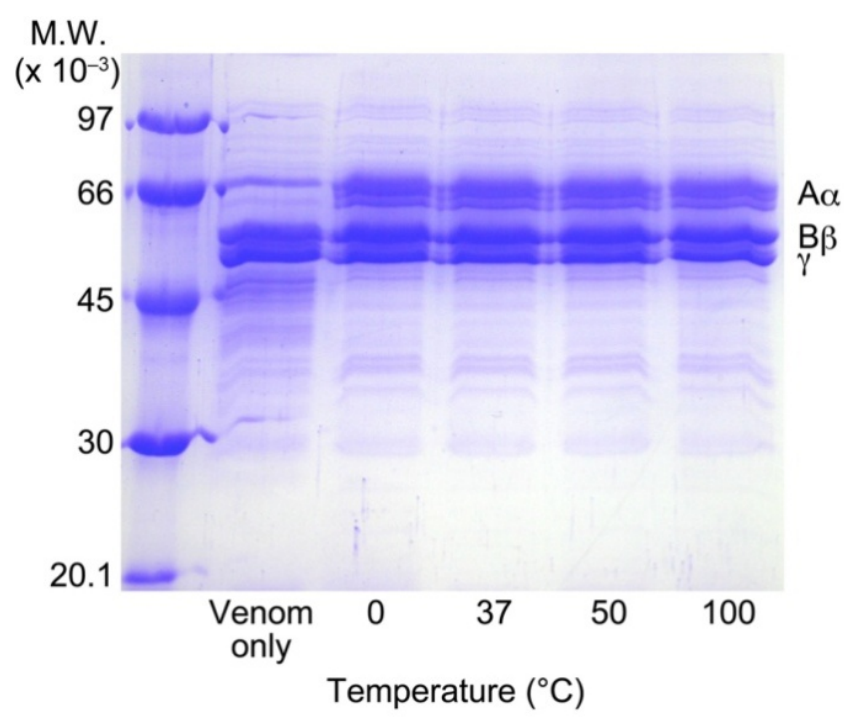

\subsection{Inhibition of Venom-Induced Edema}

The edema-forming activity was assayed using four mice. T. elegans venom induced an edema of $30 \%$ in the mouse footpad, at a dose of $12.5 \mu \mathrm{g}$. When T. elegans venom was preincubated with RA $(0.5 \mathrm{mg} / \mathrm{mL})$, the edema-forming was significantly reduced. 


\section{Discussion}

RA effectively inhibited snake venom induced hemorrhage by crude venoms of $T$. flavoviridis, Crotalus atrox, Gloydius blomhoffii, and B. arietans or purified toxins (HTb, bilitoxin-2, HT-1 and $\mathrm{Ac}_{1}$-proteinase) [10]. As shown in Figure 7, envenomation by snakebites often produces persistent hemorrhage due to considerable degradation of fibrinogen and other coagulation factors, thus preventing clot formation [21]. The pathogenesis of venom-induced hemorrhage involves direct damage to endothelial cells in microvessels by hemorrhagic toxins [22,23]. Snake venom metalloproteinases (especially snake venom metalloproteinase from $T$. flavoviridis venom) degrade the most important components of the basement membrane, such as laminin, type IV collagen and nidogen/entactin [24-26]. In this study, an attempt was made to determine the protective effects of RA on digestion of human fibrinogen, digestion of type IV collagen and cytotoxic action on HUVEC induced by $T$. flavoviridis venom. The pure compound showed antifibrinogenolytic activity by inhibiting the digestion of the A $\alpha$ chain of human fibrinogen. RA also effectively inhibited HUVEC against the toxic action of $T$. flavoviridis venom at various concentrations and digestion of type IV collagen. Moreover, the pathological study of thigh muscles showed that RA inhibited hemorrhage and neutrophil infiltrations. T. flavoviridis venom-induced lethality was significantly antagonized by RA $(960 \mu \mathrm{g})$, whereas the venom is highly lethal to mice with $200 \mu \mathrm{g}$. The compound inhibited the edema-forming effect of T. elegans venom and lethal action induced by $T$. flavoviridis venom. The aforementioned evidence demonstrates that RA inhibited most of the hemorrhage effects of venom (Figure 7). It has been reported that RA isolated from Cordia verbenacea (Boraginaceae) inhibits the edema and myotoxic activity induced by crude venom and isolated $\mathrm{PLA}_{2} \mathrm{~S}$ [27]. However, the mechanisms of action of $\mathrm{PLA}_{2} \mathrm{~S}$ are quite different from those of metalloproteinases. This is the first report of RA that demonstrates the inhibitory mechanism for snake venom induced hemorrhage and protection from snakebite envenomation.

Figure 7. Mechanisms of hemorrhage induction by snake venom, and points of action of RA for inhibition of hemorrhage.

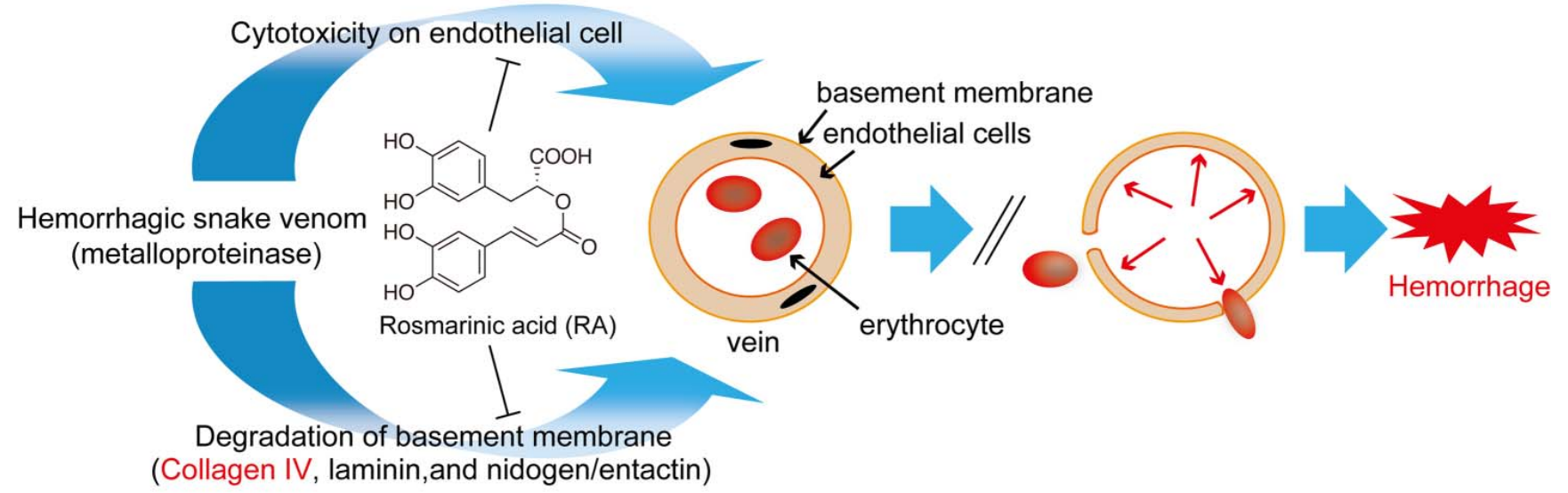


In this study, the inhibitory activities of rosmarinic acid from Argusia argentea against the action of snake venom were investigated. The plant is found on tropical shores of the Pacific and Indian oceans and the extract of the leaves are locally used as an antitoxin for snakebites and fish poisoning [28,29]. In the Okinawa islands, the leaves of Argusia argentea are the first medical treatment against snake venom as well as against jellyfish venom [30]. Hemorrhage is a conspicuous sequela of envenomation by Viperidae. Hemorrhage from damage to the vascular endothelium of vital organs causes death [31]. These observations confirmed that RA possesses potent snake venom neutralizing properties. Furthermore, the heat stability of RA would satisfy a requirement for a first-aid treatment for snakebite. Because snakebites often occur outdoors far from medical institutions, it is necessary to distribute a drug to distant locations without refrigeration, and the drug must be storable at room temperature. Further studies are needed to investigate post-administration of RA, and the effects of different methods of administration. After these issues are resolved, RA could become a potent alternative antidote compound for snake envenomation.

\section{Acknowledgements}

This work was supported by the bounty for academic research from the Research Institute of Meijo University. One of the authors (H.T.A.) is supported by the Japanese Government (MEXT) Scholarship 2007 to study in Japan.

\section{References}

1 Warrell, D.A. The global problem of snakebite: Its prevention and treatment. In Recent Advances in Toxinology Research; Gopalakrishnakone, P., Tu, C.K., Eds.; National University of Singapore: Singapore, 1992; pp. 121-153.

2 Chippaux, J.P. Snake-bites: Appraisal of the global situation. Bull. World Health Organ. 1998, 76, 515-524.

3 Swaroop, S.; Grab, B. Snakebite mortality in the world. Bull. World Health Organ. 1954, 10, $35-76$.

4 Theakston, R.D.G.; Reid, H.A. Development of simple standard assay procedures for the characterization of snake venom. Bull. World Health Organ. 1983, 61, 949-956.

5 Tu, A.T. Venoms: Chemistry and Molecular Biology; Wiley: New York, NY, USA, 1977.

6 Tu, A.T. Rattlesnake Venoms: Their actions and Treatment; Dekker: New York, NY, USA, 1982.

7 Martz, W. Plants with a reputation against snakebite. Toxicon 1992, 30, 1131-1142.

8 Mors, W.B.; Nascimento, M.C.; Pereira, B.M.; Pereira, N.A. Plant natural products active against snake-bite — the molecular approach. Phytochemistry 2000, 55, 627-642.

9 Soares, A.M.; Januario, A.H.; Lourenco, M.V.; Pereira, A.M.; Pereira, P.S. Neutralizing effects of Brazilian plants against snake venoms. Drugs Future 2004, 29, 1105-1117.

10 Aung, H.T.; Nikai, T.; Niwa, M.; Takaya, Y. Rosmarinic acid in Argusia argentea inhibits snake venom-induced hemorrhage. J. Nat. Med. 2010, 64, 482-486. 
11 Komori, Y.; Hagihara, S.; Tu, A.T. Specificity of hemorrhagic proteinase from Crotalus atrox (western diamondback rattlesnake) venom. Biochim. Biophys. Acta 1985, 829, 127-130.

12 Nikai, T.; Taniguchi, K.; Komori, Y.; Sugihara, H. Hemorrhagic toxin, bilitoxin-2, from Agkistrodon bilineatus venom. J. Nat. Toxins 1996, 5, 95-106.

13 Nikai, T.; Sugihara, H.; Tanaka, T. Enzymochemical studies on snake venoms II. Purification of lethal protein Ac1-proteinase in the venom of Agkistrodon acutus. Yakugaku Zasshi 1977, 97, 507-514.

14 Nikai, T.; Suzuki, J.; Komori, Y.; Sugihara, H. Biochemical and pathological studies on hemorrhagic toxin. J. Nat. Toxins 1995, 4, 83-96.

15 Bjarnason, J.B.; Tu, A.T. Hemorrhagic toxins from western diamondback rattlesnake (Crotalus atrox) venom: Isolation and characterization of five toxins and the role of zinc in hemorrhagic toxin e. Biochemistry 1978, 17, 3395-3404.

16 Ouyang, C.; Teng, C.M. Fibrinogenolytic enzymes of Trimeresurus mucrosquamatus venom. Biochim. Biophys. Acta 1976, 420, 298-308.

17 Ishiyama, M.; Miyazono, Y.; Sasamoto, K.; Ohkura, Y.; Ueno, K. A highly water-soluble disulfonated tetrazolium salt as a chromogenic indicator for NADH as well as cell viability. Talanta 1997, 44, 1299-1305.

18 Tominaga, H.; Ishiyama, M.; Ohseto, F.; Sasamoto, K.; Hamamoto, T.; Suzuki, K.; Watanabe, M. A water-soluble tetrazolium salt useful for colorimetric cell viability assay. Anal. Commun. 1999, $36,47-50$.

19 Komori, Y.; Nikai, T.; Taniguchi, K.; Masuda, K.; Sugihara, H. Vascular endothelial growth factor VEGF-like heparin-binding protein from the venom of Vipera aspis aspis (Aspic Viper). Int. J. Biochem. 1999, 38, 11796-11803.

20 Ho, C.L.; Hwang, L.L.; Chen, C.T. Edema-inducing activity of a lethal protein with phospholipase $\mathrm{A}_{1}$ activity isolated from the black-bellied hornet (Vespa basalis) venom. Toxicon 1993, 31, 605-613.

21 Laing, G.D.; Moura-da-Silva, A.M. Jararhagin and its multiple effects on hemostasis. Toxicon 2005, 45, 987-996.

22 Bjarnason, J.B.; Fox, J.W. Hemorrhagic metalloproteinases from snake venoms. Pharmacol. Ther. 1994, 62, 325-372.

23 Markland, F.S. Snake venoms and the hemostatic system. Toxicon 1998, 36, 1749-1800.

24 Baramova, E.N.; Shannon, J.D.; Bjarnason, J.B.; Fox, J.W. Degradation of extracellular matrix proteins by hemorrhagic metalloproteinases. Arch. Biochem. Biophys. 1989, 275, 63-71.

25 Baramova, E.N.; Shannon, J.D.; Bjarnason, J.B.; Fox, J.W. Identification of the cleavage sites by a hemorrhagic metalloproteinase in type IV collagen. Matrix 1990, 10, 91-97.

26 Mashiko, H.; Takahashi, H. Haemorrhagic factors from snake venoms. II. Structures of haemorrhagic factors and types and mechanisms of haemorrhage. J. Toxicol. Toxin Rev. 1998, 17, 493-512. 
27 Ticli, F.K.; Hage, L.I.S.; Cambraia, R.S.; Pereira, P.S.; Magro, A.J.; Fontes, M.R.M.; Stábeli, R.G.; Giglio, J.R.; França, S.C.; Soares, A.M.; Sampaio, S.V. Rosmarinic acid, a new snake venom phospholipase $\mathrm{A}_{2}$ inhibitor from Cordia verbenacea (Boraginaceae): Antiserum action potentiation and molecular interaction. Toxicon 2005, 46, 318-327.

28 Ogihara, K.; Miyagi, Y.; Higa, M.; Yogi, S. Pyrrolizidine alkaloids from Messerschmidia argentea. Phytochemistry 1997, 44, 545-547.

29 Noro, T.; Nishihara, G.N.; Terada, R.; Yoropiy, A. Ciguatera Fish Poisoning in Ulithi Atoll, Yap State, Micronesia. Kagoshima Univ. Res. Ctr. Pac. Isl. Occas. Pap. 2003, 39, 83-86.

30 Ogihara, K.; Nakazato, R.; Nishi, Y.; Higa, M.; Yogi, S. DPPH-radical scavenging constituents from the twigs of Messerschmidia argentea. Bull. Fac. Sci. Univ. Ryukyus 2002, 74, 73-80.

31 Warrell, D.A. Russell's viper: biology, venom and treatment of bites. Trans. R. Soc. Trop. Med. Hyg. 1989, 83, 732-740.

(C) 2010 by the authors; licensee MDPI, Basel, Switzerland. This article is an open access article distributed under the terms and conditions of the Creative Commons Attribution license (http://creativecommons.org/licenses/by/3.0/). 